Research Article

\title{
Silver Nanoparticles as an Effective Anti- Nanobacterial System towards Biofilm Forming Pseudomonas oryzihabitans
}

\author{
Shaimaa Obaid Hasson ${ }^{1}$, Mohammed Jabber Al-Awady ${ }^{2}$, Mohanad Jawad Kadhim², \\ Hayder Shkhair Al-Janabi ${ }^{2}$ \\ ${ }^{1}$ Department of Microbiology, College of Veterinary, Al-Qasim Green University, Babylon, Iraq. \\ ${ }^{2}$ Department of Genetic Engineering, Faculty of Biotechnology, Al Qasim Green University, Babylon, Iraq. \\ Corresponding author. E-mail: shaimaaobead@gmail.com
}

Received: Jun. 18, 2019; Accepted: Aug. 22, 2019; Published: Aug. 23, 2019.

Citation: Shaimaa Obaid Hasson, Mohammed Jabber Al-Awady, Mohanad Jawad Kadhim, and Hayder Shkhair Al-Janabi, Silver Nanoparticles as an Effective Anti-Nanobacterial System towards Biofilm Forming Pseudomonas oryzihabitans. Nano Biomed. Eng., 20 I 9, I I (3): 297-305. DOI: 10.5101/nbe.v11i3.p297-305.

\begin{abstract}
Silver nanoparticles have been considered a powerful antimicrobial agents recently especially after increasing incidence of diseases associated with biofilm and multi-drug resistant pathogens required to find a novel path to eradicate that challenge. The present study aims to evaluate the antibacterial activity of biosynthesized silver nanoparticles (AgNPs) using a cell-free extract of Enterobacter cloacae and chemo synthesis by sodium borohydride $\left(\mathrm{NaBH}_{4}\right)$ on biofilm-forming Pseudomonas oryzihabitans. Antimicrobial effect of silver nanoparticles in both types and in combination with imipenem were evaluated by agar well diffusion method. The results revealed a good response to inhibit biofilm-forming Pseudomonas oryzihabitans growth by silver nanoparticles antibacterial activity in both types (biological and chemical) and in combination with imipenem; the antimicrobial effect was increased and enhanced. In the present study, it was found that the biological and chemical silver nanoparticles were considered a novel and decisive solution against biofilm and multi- drug resistance bacteria with a preference of biological silver nanoparticles.
\end{abstract}

$\overline{\text { Keywords: Biological silver NPs; Chemical silver NPs; Biofilm; Pseudomonas oryzihabitans; }}$ Imipenem

\section{Introduction}

Silver-ions have been reported to possess strong biocidal effects [1]. The silver-compounds are used as disinfection agents from the ancient time [2]. Nanoparticles have dimension less than $100 \mathrm{~nm}$ [3]. Silver nanoparticles (AgNPs) contain compounds which act as antimicrobial agents [4]. Recently, silver nanoparticles have been considered as powerful antimicrobial agents, especially with increasing incidence of diseases associated with biofilm and multi-drug resistance pathogens which are necessarily required to find a novel path to eradicate that challenge. Moreover, there are wide range of studies focusing on AgNPs antimicrobial activity [5]. They possess a high activity against microorganisms (bacteria, fungi, and virus) but the mechanism of action still mostly unknown [6].

Silver has long standing antibacterial compound, and silver nanoparticles are more potent in antimicrobial 
effect than normal scale [7, 8]. Silver nanoparticles increase bacterial susceptibility to antibiotics when combined with them as synergistic effect especially in biofilm infection [9], for example, nitrofurazone increased its effect in silver present [10].

Studies have pointed out that silver is non-toxic, safe, and may not accumulate or cause harmful effects to human body, so silver nanoparticles have been used in the medical field as wound dressing, heart valves and face mask [11]. Many methods such as chemical and biological methods have been used to synthesize silver nanoparticles [12]. Most researchers tend to use the biological method because it is eco-friendly, inexpensive and more antimicrobial-effective than other methods. Many microorganisms like bacteria $[13,14]$ can produce nanoparticles through two routes; intracellular and extracellular [3, 15]. The intracellular route deals with mixing the filtrate of the bacterial cell with metal salt then kept in a shaker incubator in dark condition [16]. And on the other hand, the extracellular route relies on using bacterial supernatant after centrifuging at $8000 \mathrm{rpm}$ then mixing with metal salt, and incubating in dark condition [17]. In principle, the microorganism can synthesize nanoparticles by redoxing enzymes which are produced by bacterial activities, then act as electron shuttle to snatch the target ions from its environment to reduce the metal ions to nanoparticles $[3,18]$, which lead to precipitate the product nanoparticles on cell external environment [18]. In biological synthesis method, the protein responsible for ion reduction is found to secret at a large amount [19].

The chemical method used in nanoparticles synthesis is the chemical reduction, which reduces the metal ions to nano-sized particles by reduction agents such as sodium citrate, sodium borohydride, elemental hydrogen, ascorbate, etc. [20, 21]. Biofilm is aggregation of bacterial communities embedded in exopolysaccharide matrix (EPS). Bacteria within biofilm communication tend to resist antibiotics and avoid a host immune system. The EPS protects biofilm bacteria from antibiotics action by shielding it [22]. Based on the emergence of pathogenic bacterial strains, especially biofilm-forming bacteria have ability to develop antibiotics resistant to be multi-drug resistant bacteria. The medical world is in urgent need of a new way to eradicate and kill biofilm-forming bacteria. AgNPs are the most promising antimicrobial agents to fill this role [23-25]. The present study aims to evaluate the antibacterial activity of biosynthesized AgNPs using a cell-free extract of Enterobacter cloacae and chemo synthesis by $\mathrm{NaBH}_{4}$ (sodium borohydride) on biofilm-forming Pseudomonas oryzihabitans.

\section{Experimental \\ Bacterial isolates}

Biofilm-forming bacterial isolates ( $P$. oryzihabitans) were isolated and identified according to previous study [26].

\section{Preparation and characterization of silver nanoparticles}

The chemical method for the preparation of silver nanoparticles was carried out according to the procedure described by Hasson et al. [9] with some modifications. Briefly, silver nanoparticles were synthesized chemically using sodium borohydride as reducing agent and silver nitrate $\left(\mathrm{AgNO}_{3}\right)$ as a precursor ( $5 \mathrm{~mL}$ of $0.01 \mathrm{M} \mathrm{AgNO}_{3}$ was added dropwise ( 1 drop per sec.) to $50 \mathrm{~mL}$ of $0.001 \mathrm{M} \mathrm{NaBH}_{4}$ ). On the other hand, the biosynthesis of silver nanoparticles was accomplished by using supernatant free Enterobacter cloacae as reducing agents with aliquot of silver nanoparticles: $0.25 \mathrm{~mL}$ of $0.1 \mathrm{M} \mathrm{AgNO}_{3}$ was added to $50 \mathrm{~mL}$ of $10 \mathrm{~mL}$ bacterial supernatant (E. cloacae) and $40 \mathrm{~mL}$ deionized water.

To calculate the final concentrations of nanoparticles' production in both types, the following steps were followed:

Final concentration (con.) of chemosynthesis AgNPs: N1V1=N2V2, N1 $\times 50=0.01 \times 5=0.001$.

Then, final con. $=\mathrm{N} 1 \times \mathrm{MW}$ of $\mathrm{AgNO}_{3} \times 1000$, $0.001 \times 170 \times 1000=170 \mu \mathrm{g} / \mathrm{mL}$. And the biological synthesis was: $\mathrm{N} 1 \mathrm{~V} 1=\mathrm{N} 2 \mathrm{~V} 2=\mathrm{N} 1 \times 50=0.1 \times 0.25$ $=0.0005 \mathrm{M}$. Then, final con. $=\mathrm{N} 1 \times \mathrm{MW}$ of $\mathrm{AgNO}_{3} \times$ $1000=0.0005 \times 170 \times 1000=85 \mu \mathrm{g} / \mathrm{mL}$.

The AgNPs for both methods were characterized using ultraviolet-visible spectroscopy (UV-Vis), Fourier-transform infrared spectroscopy (FTIR), particle size distribution and zeta potential as mentioned by Al-Azawi et al. and Hasson et al. [27, 28].

\section{Antimicrobial susceptibility assay of silver nanoparticles}

Antimicrobial activity of the bio- and chemosynthesized AgNPs was evaluated using the agar well diffusion method. This method was carried out according to CLSI [29] by preparing biofilm-forming 
$P$. oryzihabitans inoculum at turbidity equivalent to McFarland tube standard at $1.5 \times 10^{8} \mathrm{CFU} / \mathrm{mL}$, then seeded by streaking method on Muller Hinton agar plate and then waited for 10 min to dry. Afterwards, 5 wells were made by cork borer at $8 \mathrm{~mm}$ and each filled with $100 \mu \mathrm{L}$ from either chemically synthesized AgNPs solution at different concentrations (170, 150, 130, 110 and $90 \mu \mathrm{g} / \mathrm{mL}$ ) or biologically synthesized AgNPs with different concentrations $(85,65,45,25$ and $5 \mu \mathrm{g}$ / $\mathrm{mL}$ ). All plates were incubated at $37^{\circ} \mathrm{C}$ for $24 \mathrm{~h}$, with dark conditions. Both AgNPs types were diluent by deionized water [30]. After incubation, the inhibition zone diameter was measured by ruler to nearest whole millimeter.

The results of both types were compared with related bacterial reference strains as control.

\section{Combination of chemo- and bio-synthesized AgNPs with the antibiotic}

The test was carried out according to Verma [31] using well diffusion agar to determine the antibacterial effect of AgNPs (chemical and biological) in combination with imipenem. As mentioned above about streaking biofilm-forming $P$. oryzihabitans on Muller Hinton agar, many wells were made by cork borer and each well contained $100 \mu \mathrm{L}$ from both (50 $\mu \mathrm{L}$ from each one): Imipenem concentration at $8,4,2$, $1,0.5,0.25$ and $0.125 \mu \mathrm{g} / \mathrm{mL}$ (antibiotic con. according to CLSI, 2017 MIC values [29]) with chemical AgNPs concentration at $170,150,130,110,90,70$ and $50 \mu \mathrm{g} /$ $\mathrm{mL}$ to be $170 / 8,150 / 4,130 / 2,110 / 1,90 / 0.5,70 / 0.25$ and 50/0.125, and with biological AgNPs concentration at $85,65,45,25$ and $5 \mu \mathrm{g} / \mathrm{mL}$ to be $85 / 8,65 / 4$. 45/2. $25 / 1$ and $5 / 0.5$. All plates were incubated at $37^{\circ} \mathrm{C}$ for $24 \mathrm{~h}$, with dark conditions. After incubation time, the inhibition zone diameter was measured by ruler to nearest whole millimeter. The synergistic effect was calculated according to equation [31]: Synergistic effect $=[(\mathrm{B}-\mathrm{A}) / \mathrm{A}] \times 100$, where $\mathrm{A}=$ zone of inhibition (ZOI) for antibiotic and $\mathrm{B}=\mathrm{ZOI}$ for antibiotics $+\mathrm{Ag}$ NPs

\section{Statistical analysis:}

Statistical analysis was done by using t-test and one way ANOVA at $p$-value 0.05 by SPSS Statistics 24.0 software.

\section{Results and Discussion}

AgNPs were considered effective against bacteria resistant to antibiotics, as well as against fungi and viruses [2]. The chemical synthesis of AgNPs was accomplished by using $\mathrm{NaBH}_{4}$ as reducing agent which reduces silver nitrate to AgNPs [32], while the biological synthesis method is simple and lowcost approach for the preparation of stable AgNPs by reduction of silver nitrate solution using supernatant free Enterobacter cloacae as a result of the presence of nitrate reductase enzyme.

Nitrate reductase in bacteria is the main enzyme concerning silver nanoparticles synthesis [33]. The reduction of this enzyme functions as an NADPH dependent nitrate reductase metal ion ( $\mathrm{Ag}^{+}$ions) to synthesize nanoparticles (silver NPs). The enzyme acts to convert the nitrate to nitrite [34], and then shuttles the electron to silver ions [20]. The characterization of the produced AgNPs was conducted in two ways as follows:

\section{Visual inspection}

The visual inspection of the produced chemical and biological AgNPs revealed dark brown or brown instead of colorless $\mathrm{AgNO}_{3}$ (Fig. 1(a) and (b)), and that change in color occurred after adding reduction agents $\left(\mathrm{NaBH}_{4}\right.$ or bacterial supernatant) related to reduction indicator to convert $\mathrm{Ag}^{+}$to $\mathrm{Ag}^{0}$ to be nanoparticles. In chemical AgNPs, the color increased in degree to be dark brown when continuing mixing with magnetic stirrer for $0.5 \mathrm{~h}$. In biological AgNPs, change in the color was previously reported in many extracellular synthesis methods from bacterial source [35] and from Enterobacter cloacae especially [13]. The brown color in both methods is related to the excitation of AgNPs surface Plasmon vibration [36] as a result of AgNPs production.

\section{Ultraviolet-visible spectroscopy (UV-Vis)}

The observation of biological AgNPs synthesized by E. cloacae was strong with narrow surface peak reaching to $400 \mathrm{~nm}$ (Fig. 1(c)). Narrow peak indicates narrow size range of nanoparticles less than $100 \mathrm{~nm}$ [13].

Yes in chemical AgNPs, UV-visible absorption spectrophotometer revealed the absorption band was at 390 nm (Fig. 1(c)) due to AgNPs Plasmon resonance. The absorption energy of AgNPs depends on Plasmon resonance degree which represents the ratio of silver ion to silver zero valent [32]. 

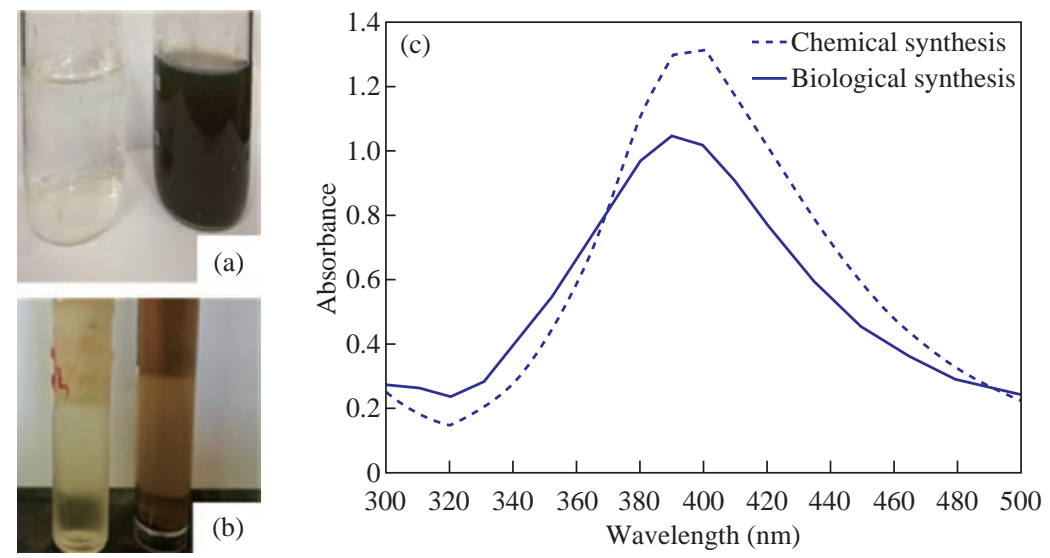

Fig. 1 (a) Color profile for the synthesized silver NPs using chemical method through reduction of silver ions with sodium borohydride as a reducing agent. (b) Color profile for the biosynthesized silver NPs using secondary metabolites of bacteria. (c) UVvisible absorption spectrum of chemically and biologically synthesized silver nanoparticles.

UV-visible absorption spectra of AgNPs were due to surface plasmon resonance absorption because of the vibration combination of AgNPs free electrons with light wave, and also it was considered as another indicator of nanoparticles production at the range of absorption from 390-420 $\mathrm{nm}$ [37].

\section{Size analyzer}

The AgNPs size of both methods was determined by dynamic light scattering. The nanoparticle distribution analysis of chemically synthesized AgNps revealed the average particle size was approximately $22-28 \mathrm{~nm}$
$(25 \pm 3)$ (Fig. 2(a)), while the size of biosynthesized AgNPs was 56-70 nm (63 \pm 7 ) (Fig. 2(b)).

The antibacterial activity of AgNPs bears the influence of the particle size. Small particles are well known to be more effective than large ones in terms of antibacterial and antibiofilm performance [38]. Many previous studies reported that antibacterial activity was based on the particle size of AgNPs [39].

The size of nanoparticles has a crucial role in the field of biomedicine. In blood stream, the size regulates navigation and circulation of NPs. In addition, to affect penetration the drug across the physiological barriers,

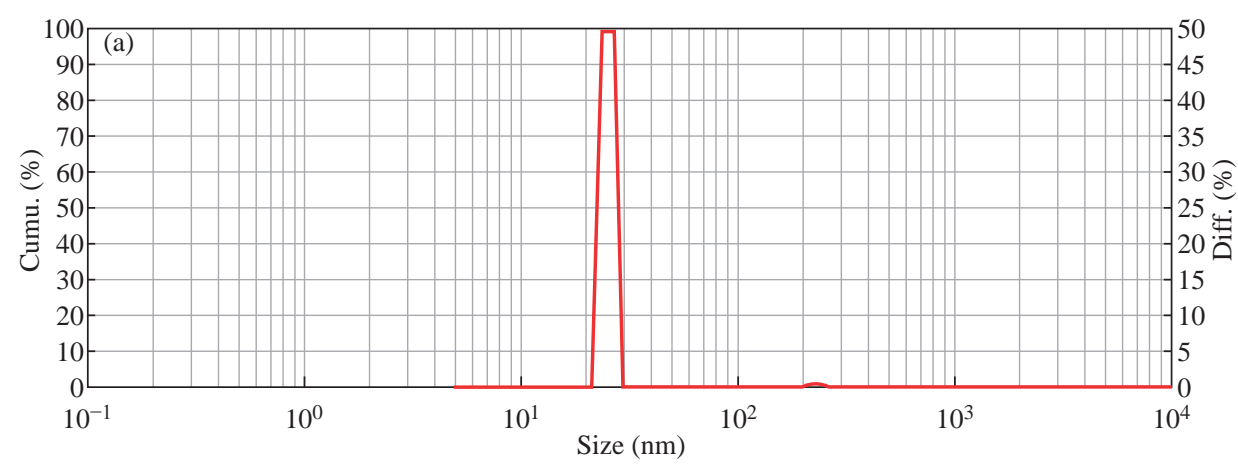

\begin{tabular}{|c|c|}
\hline Diam (nm) & Percent (\%) \\
\hline 22.3 & 0.00 \\
\hline 29.9 & 99.04 \\
\hline 40.1 & 99.04 \\
\hline 53.9 & 99.04 \\
\hline 72.3 & 99.04 \\
\hline 97.0 & 99.04 \\
\hline 130 & 99.04 \\
\hline 174 & 99.04 \\
\hline 234 & 99.57 \\
\hline 315 & 100.00 \\
\hline
\end{tabular}

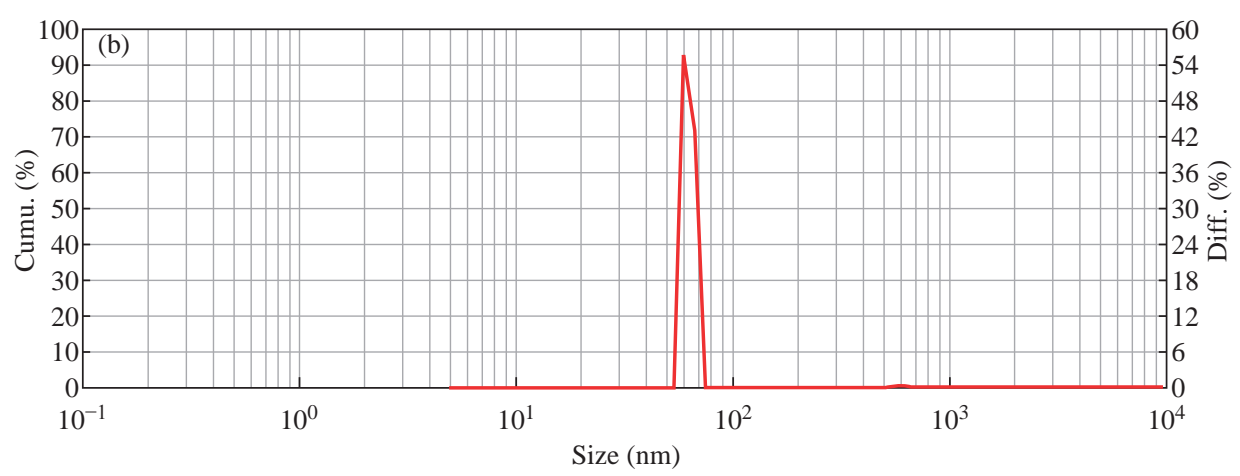

\begin{tabular}{|c|c|}
\hline Diam (nm) & Percent (\%) \\
\hline 56.1 & 0.00 \\
\hline 75.2 & 99.27 \\
\hline 101 & 99.27 \\
\hline 135 & 99.27 \\
\hline 181 & 99.27 \\
\hline 244 & 99.27 \\
\hline 327 & 99.27 \\
\hline 439 & 99.27 \\
\hline 590 & 99.69 \\
\hline 792 & 100.00 \\
\hline
\end{tabular}

Fig. 2 (a) Average particle diameter of chemo-synthesized AgNPs. (b) Average particle diameter of biosynthesized AgNPs. 
localization on specific site and cellular responses induction $[40,41]$.

\section{Antimicrobial effects of AgNPs on biofilm bacteria}

Antimicrobial activity of the chemo- and biosynthesized AgNPs was evaluated using the agar well diffusion method on biofilm-forming P. oryzihabitans.

\section{Agar well diffusion method}

The test was conducted on biological and chemical AgNPs in different concentrations to biofilm $P$. oryzihabitans and the control. AgNPs inhibit biofilm formation of P. oryzihabitans [2]. The results revealed that AgNPs' antibacterial activity increased with its concentration rising in both types (chemical and biological AgNPs) (Figs. 3-6), which was close to our previous results [9]. The statistical analysis showed that there was a significant difference among biofilm activity of P. oryzihabitans isolates of chemical AgNPs with $p=0.03$ (Table 1), while there was no significant difference among isolates in biological AgNPs' activity with $p=0.734$ (Table 2). Recently, other researchers developed chip technique which revealed that AgNPs were able to eradicate $P$. aeruginosa biofilms

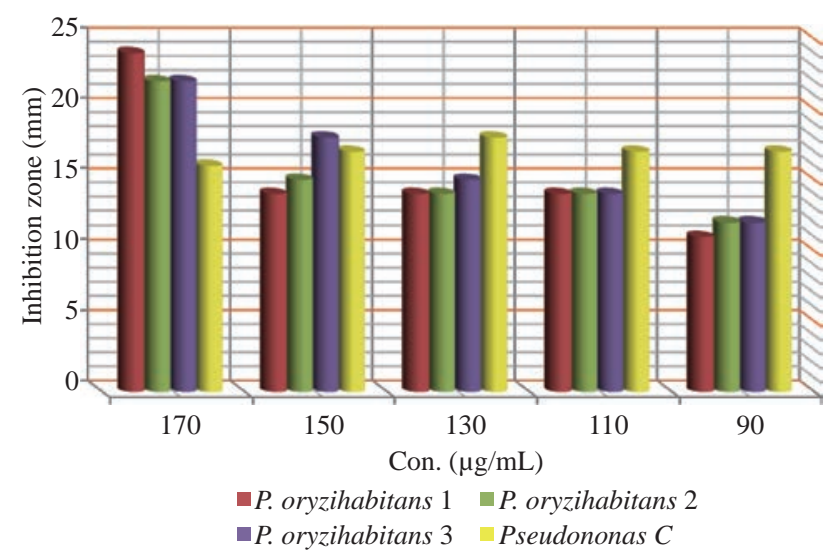

Fig. 3 Zone of growth inhibition (mm) of chemical AgNPs against biofilm $P$. oryzihabitans and P. aeruginosa as control.
Table 1 Statistical analysis of antibacterial effect of chemical AgNPs on biofilm P. oryzihabitans isolates

\begin{tabular}{ccc}
\hline $\begin{array}{c}\text { AgNPs con. } \\
(\mu \mathrm{g} / \mathrm{mL})\end{array}$ & $\begin{array}{c}\text { Zone of inhibition } \\
(\text { mean } \pm \mathrm{SE})\end{array}$ & $p$-value \\
\hline 170 & $21.0000 \pm 1.73205$ & \\
150 & $16.0000 \pm 0.91287$ & \\
130 & $15.2500 \pm 0.94648$ & 0.03 \\
110 & $14.7500 \pm 0.75000$ & \\
90 & $13.0000 \pm 1.35401$ & \\
\hline
\end{tabular}

Table 2 Statistical analysis of antibacterial effect of biological AgNPs on biofilm P. oryzihabitans isolates

\begin{tabular}{ccc}
\hline $\begin{array}{c}\text { AgNPs con. } \\
(\mu \mathrm{g} / \mathrm{mL})\end{array}$ & $\begin{array}{c}\text { Zone of inhibition } \\
(\text { Mean } \pm \mathrm{SE})\end{array}$ & $p$-value \\
\hline 85 & $15.7500 \pm 1.43614$ & \\
65 & $14.5000 \pm 0.86603$ & \\
45 & $16.2500 \pm 2.92617$ & 0.734 \\
25 & $16.0000 \pm 3.00000$ & \\
5 & $12.7500 \pm 0.75000$ & \\
\hline
\end{tabular}

completely when treated at $0.5 \mu \mathrm{g} / \mathrm{mL}$ [22].

The antibacterial effect of AgNPs is an electrostatic interaction between nanoparticles and bacterial cell membrane to disrupt it by modified membrane morphology to increase its permeability, which converts the bacterial cell enable to regulate transport mechanism leading to cell death $[42,43]$. In addition to producing free radicals (ROS) which prompted the damage of a cell membrane, the inhibiting function of protein and destruction of DNA result in excess free radical production [43]. The destabilization of a cell membrane and reduction of adenosine triphosphate (ATP) level in bacterial cell can kill it [44]. Thus, AgNPs are considered a broad-spectrum antibacterial agent [45]. AgNPs also interact strongly with thiol group, leading to destructing the vital enzyme, also binding to thiol and amino group to disrupt protein synthesis in the cell wall and causing loss of DNA

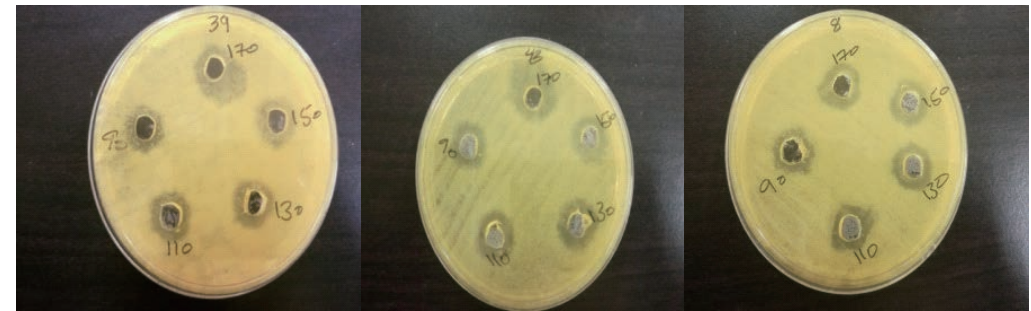

(a)

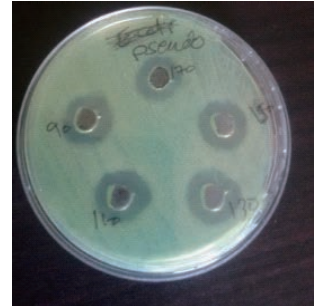

(b)

Fig. 4 Antibacterial activity of chemical AgNPs on biofilm P. oryzihabitans isolates: (a) P. oryzihabitans 3 isolates; (b) Non-biofilm P. aeruginosa as control. 


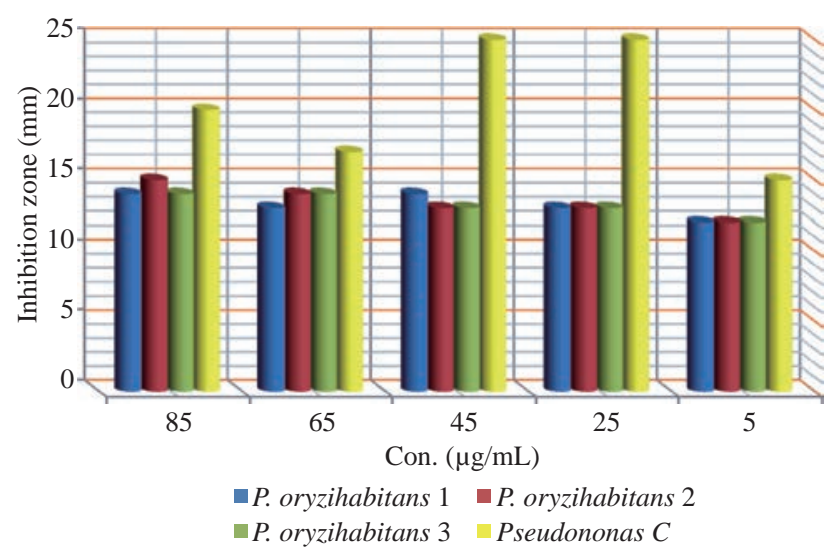

Fig. 5 Zone of growth inhibition (mm) of biological AgNPs against biofilm P. oryzihabitans and P. aeruginosa as control.

by inhibiting its replication [46, 47]. It occurs when AgNPs destruct cell wall permeability and then could invade bacterial cell into cytoplasm and interact with DNA to avoid the replication process which leads to cell death [48].

Moreover, several authors reported that AgNPs inclined to accumulate at the bacterial membrane, and diminution integrity of the bacterial membrane, which led to cellular death $[42,49]$.

Biological AgNPs seemingly were more effective against biofilm P. oryzihabitans than chemical AgNPs, but statistical analysis showed no significant difference between them with $p=0.420$ (Table 3 ).

\section{Combination both types of AgNPs with imipenem}

From the previous study [26], it was found that imipenem antibiotic was the most effective antibiotic on biofilm P. oryzihabitans. To study the synergism effect between AgNPs in both types and imipenem, the combination with each other was carried out.
Table 3 Statistical analysis (t-test) of antibacterial effect of AgNPs in both types on biofilm P. oryzihabitans isolates

\begin{tabular}{ccc}
\hline AgNPs type & $\begin{array}{c}\text { Zone of inhibition } \\
(\text { Mean } \pm \text { SE) }\end{array}$ & $p$-value \\
\hline Biological & $16.000 \pm 0.777$ & 0.420 \\
Chemical & $15.000 \pm 0.865$ & \\
\hline
\end{tabular}

\section{Combination chemical AgNPs with imipenem}

The results showed that antibacterial activity of AgNPs in two types of combination with imipenem was increased and enhanced on inhibiting the growth of biofilm P. oryzihabitans (Fig. 7-10). The statistical analysis showed that a significant difference existed between $P$. oryzihabitans growth inhibition and concentration value of both types of AgNPs in combination with imipenem at $p<0.01$ (Table 4 and 5). The antibacterial effect of the combination of AgNPs and antibiotic exhibited higher effect than AgNPs or antibiotic alone, which corresponded to other studies $[37,50]$. Furthermore, researchers pointed out that combined antibiotics with AgNPs brought about

Table 4 Statistical analysis of antibacterial effect of the combination of chemical AgNPs with imipenem on biofilm $P$. oryzihabitans isolates

\begin{tabular}{ccc}
\hline $\begin{array}{c}\text { AgNPs/imipenem con. } \\
(\mu \mathrm{g} / \mathrm{mL})\end{array}$ & $\begin{array}{c}\text { Zone of inhibition } \\
(\text { mean } \pm \mathrm{SE})\end{array}$ & $p$-value \\
\hline $170 / 8$ & $24.0000 \pm 0.00000$ & \\
$150 / 4$ & $21.0000 \pm 0.00000$ & \\
$130 / 2$ & $16.3333 \pm 0.33333$ & $<0.01$ \\
$110 / 1$ & $17.6667 \pm 0.88192$ & \\
$90 / 0.5$ & $13.6667 \pm 0.33333$ & \\
$70 / 0.25$ & $13.3333 \pm 0.33333$ & \\
$50 / 0.125$ & $13.3333 \pm 0.33333$ & \\
\hline
\end{tabular}

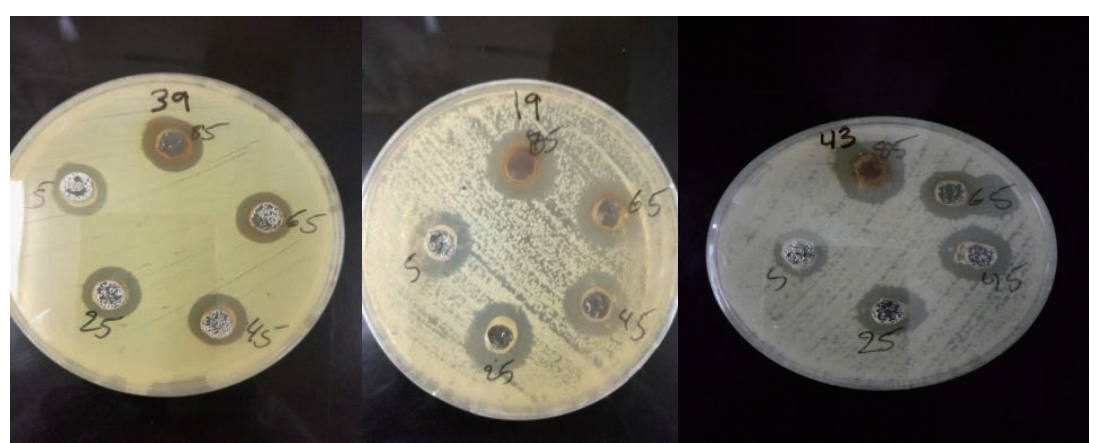

(a)

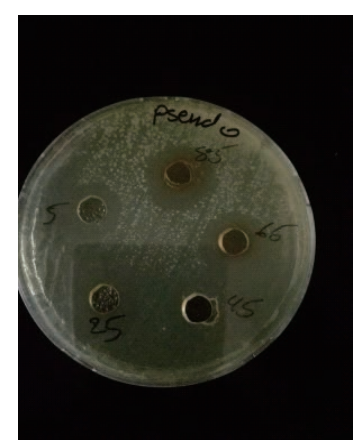

(b)

Fig. 6 Antibacterial activity of biological AgNPs on biofilm P. oryzihabitans isolates: (a) P. oryzihabitans 3 isolates; (b) Non-biofilm P. aeruginosa as control. 
Table 5 Statistical analysis of antibacterial effect of the combination of biological AgNPs with imipenem on biofilm $P$. oryzihabitans isolates

\begin{tabular}{ccc}
\hline $\begin{array}{c}\text { AgNPs } / \text { imipenem } \\
\text { conc. }(\mu \mathrm{g} / \mathrm{mL})\end{array}$ & $\begin{array}{c}\text { Zone of inhibition } \\
(\text { mean } \pm \mathrm{SE})\end{array}$ & $p$-value \\
\hline $85 / 8$ & $26.6667 \pm 0.333$ & \\
$65 / 4$ & $25.3333 \pm 0.333$ & $<0.01$ \\
$45 / 2$ & $23.3333 \pm 0.333$ & \\
$25 / 1$ & $19.6667 \pm 0.333$ & \\
$5 / 0.5$ & $13.6667 \pm 0.333$ & \\
\hline
\end{tabular}

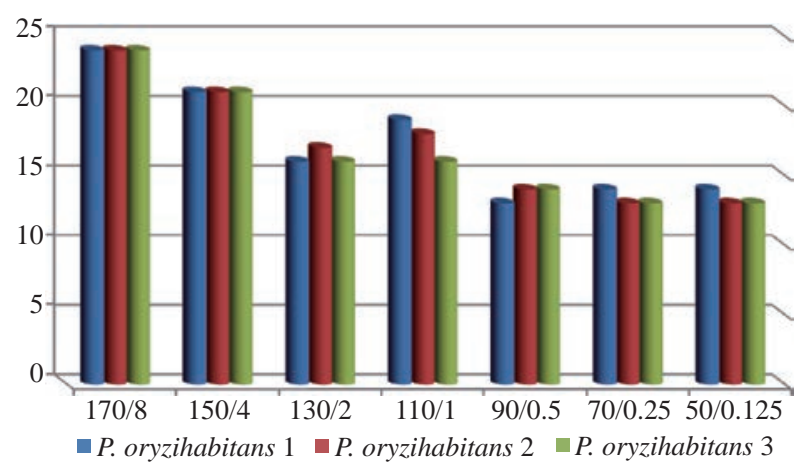

Fig. 7 Antibacterial effect of the combination of imipenem and chemical AgNPs on biofilm-forming P. oryzihabitans.
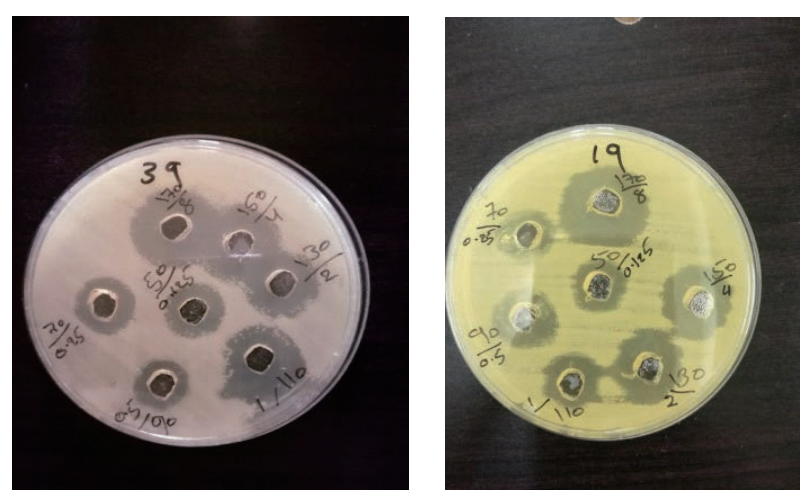

Fig. 8 Antibacterial effect of the combination of imipenem and chemical AgNPs (in different con. $(\mu \mathrm{g} / \mathrm{mL})$ ) on biofilm-forming P. oryzihabitans.

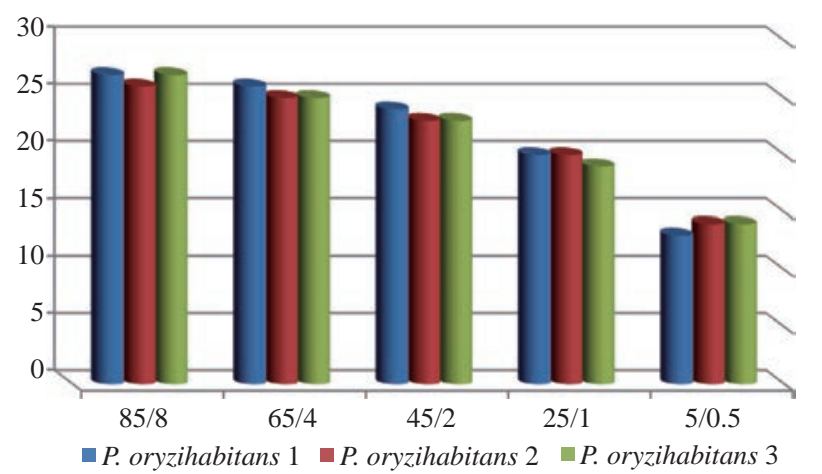

Fig. 9 Antibacterial effect of the combination of imipenem and biological AgNPs on biofilm-forming P. oryzihabitans. greater anti-biofilm activity and elevated bacterial cell death level, and so treatment with combination of antibiotics and AgNPs is considered of more potent effectiveness in terms of antibacterial and ant-biofilm performance.

Statistical analysis discovered that biological AgNPs in combination with imipenem were more effective than chemical AgNPs with imipenem, with a significant differences at $p=0.05$ (Table 6).

Results of the combination of AgNPs in two types with imipenem revealed synergistic effect against biofilm P. oryzihabitans. Table 7 and 8 show a highly synergistic effect and antibacterial activity mostly more than each one alone of both types (chemical and biological) of AgNPs to biofilm P. oryzihabitans. Antibacterial activity of AgNPs in other studies increased to reach $70 \%$ to gram-negative biofilmforming bacteria when combined with ampicillin [37]. In addition, bacterial susceptibility to antibiotics increased when combined with them as synergistic effect; especially in biofilm infection like nitrofurazone, the effect increased in the presence of silver [10].

Table 6 Statistical analysis (t-test) of antibacterial effect of the combination of both AgNPs with imipenem on biofilm $P$. oryzihabitans isolates

\begin{tabular}{ccc}
\hline AgNPs type & $\begin{array}{c}\text { Zone of inhibition } \\
(\text { mean } \pm \text { SE) }\end{array}$ & $p$-value \\
\hline Biological with imipenem & $21.733 \pm 1.255$ & 0.05 \\
Chemical with imipenem & $17.047 \pm 0.871$ & \\
\hline
\end{tabular}

Table 7 Synergism effect (\%) between chemical AgNPs and imipenem on biofilm $P$. oryzihabitans isolates

\begin{tabular}{cccc}
\hline Con. & P. oryzihabitans 1 & P. oryzihabitans 2 & P. oryzihabitans 3 \\
\hline $170 / 8$ & 0 & 9 & 9 \\
$150 / 4$ & 50 & 40 & 16 \\
$130 / 2$ & 14.2 & 21.4 & 6.6 \\
$110 / 1$ & 35.7 & 28.5 & 14.2 \\
$90 / 0.5$ & 18 & 16.6 & 16.6 \\
\hline
\end{tabular}

Table 8 Synergistic effect (\%) between biological AgNPs and imipenem on biofilm P. oryzihabitans isolates

\begin{tabular}{cccc}
\hline Con. & P. oryzihabitans 1 & P. oryzihabitans 2 & P. oryzihabitans 3 \\
\hline $85 / 8$ & 92.8 & 80 & 71.4 \\
$65 / 4$ & 100 & 85.7 & 78.5 \\
$45 / 2$ & 71.4 & 76.6 & 76.9 \\
$25 / 1$ & 53.8 & 53.8 & 46.1 \\
$5 / 0.5$ & 8.3 & 16.6 & 16.6 \\
\hline
\end{tabular}



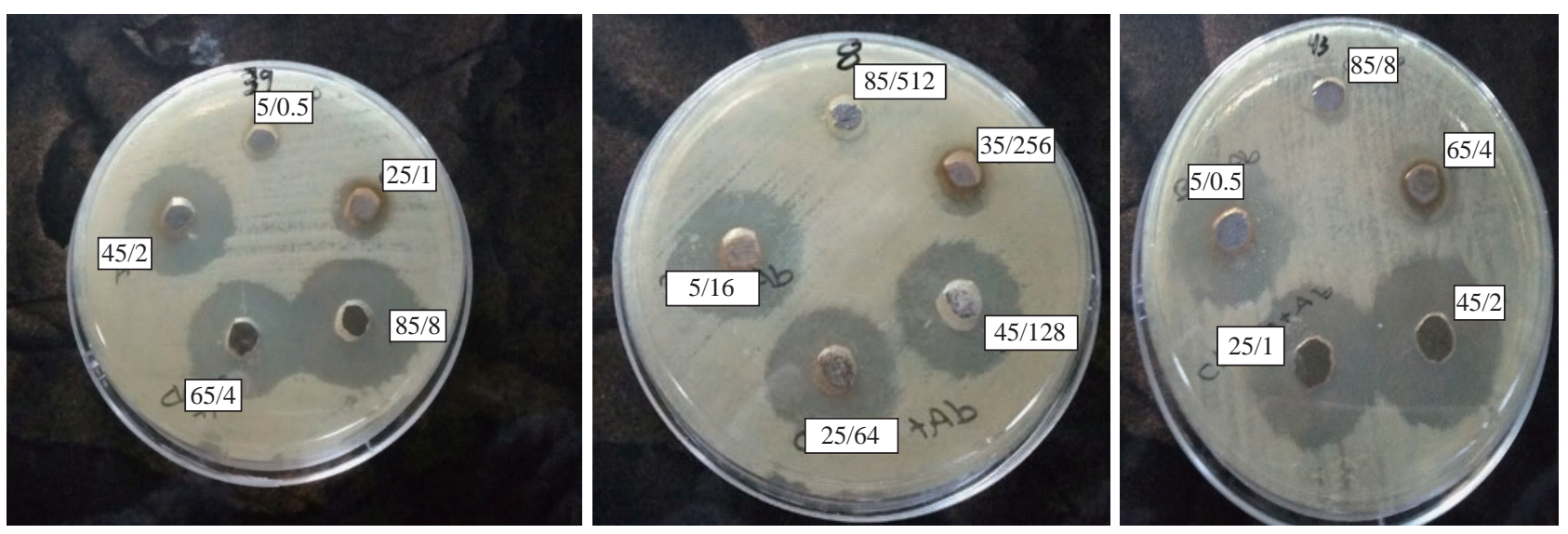

Fig. 10 Antibacterial effect of the combination of imipenem and biological AgNPs (in different con. $(\mu \mathrm{g} / \mathrm{mL})$ ) on biofilm-forming $P$. oryzihabitans.

\section{Conclusions}

In this study, the biological and chemical silver nanoparticles were considered a novel and decisive solution against biofilm and multi-drug resistant bacteria with a preference of biological silver nanoparticles. Also, the antibacterial effect of combining both types of AgNPs and imipenem exhibited a higher synergistic effect than AgNPs or antibiotic alone at a significant value.

\section{Conflict of Interests}

The authors declare that no competing interest exists.

\section{References}

[1] M. Singh, S. Prasad, and S Gambhir, Nanotechnology in medicine and antibacterial effect of silver nanoparticles. Digest Journal of Nanomaterials and Biostructures, 2008, 3(3): 115-122.

[2] M. Radzig, V.A. Nadtochenko, O.A. Koksharova, et al., Antibacterial effects of silver nanoparticles on gramnegative bacteria: influence on the growth and biofilms formation, mechanisms of action. Colloids and Surfaces B: Biointerfaces, 2013, 102: 300-306.

[3] X. Li, H. Chen, Z.S. Chen, et al., Biosynthesis of nanoparticles by microorganisms and their applications. Journal of Nanomaterials, 2011.

[4] R.E. Burrell, A scientific perspective on the use of topical silver preparations. Ostomy Wound Management, 2003, 49(5; SUPP): 19-24.

[5] R. Singh, U.U. Shedbalkar, S.A. Wadhwani, et al., Bacteriagenic silver nanoparticles: synthesis, mechanism, and applications. Applied microbiology and Biotechnology, 2015, 99(11): 4579-4593.

[6] V.K. Sharma, R.A. Yngard, and Y. Lin, Silver nanoparticles: green synthesis and their antimicrobial activities. Advances in Colloid and Interface Science, 2009, 145(1-2): 83-96.
[7] J. Sass, Nanotechnology's invisible threat: Small science, big consequences. Proceeding of the 2007 Natural Resources Defense Council. 2007.

[8] M. Prabakaran, K.V. Nithya, P. Gajendiran, et al., Green synthesis of piperine/triton X-100/silver nanoconjugates: antimicrobial activity and cytotoxicity. Nano Biomedicine and Engineering, 2018, 10(2): 141-148.

[9] S.O. Hasson, M.J. Al-Awady, A.H. Al-Hamadani, et al., Boosting antimicrobial activity of imipenem in combination with silver nanoparticles towards S. fonticola and Pantoea sp. Nano Biomed. Eng., 2019, 11(2): 200214.

[10] V. Kostenko, J.T. Lyczak, K. Martinuzzi, et al., Impact of silver-containing wound dressings on bacterial biofilm viability and susceptibility to antibiotics during prolonged treatment. Antimicrobial Agents and Chemotherapy, 2010, 54(12): 5120-5131.

[11] M.A. Theivasanthi, Anti-bacterial studies of silver nanoparticles. arXiv.org, 2011: arXiv:1101.0348 [physics. gen-ph].

[12] M.J. Al-Awady, A.A.J.N.B.E. Balakit, Investigation of anti-MRSA and anticancer activity of eco-friendly synthesized silver nanoparticles from palm dates extract. Nano Biomed. Eng., 2019, 10(2): 157-169.

[13] A.R. Shahverdi, S.S. Minaeian, H.R. Jamalifar, et al., Rapid synthesis of silver nanoparticles using culture supernatants of Enterobacteria: a novel biological approach. Process Biochemistry, 2007, 42(5): 919-923.

[14] M. Husseiny, M.A.B. El-Aziz, and M.A.Y. Mahmoud, Biosynthesis of gold nanoparticles using Pseudomonas aeruginosa. Spectrochimica Acta Part A: Molecular and Biomolecular Spectroscopy, 2007, 67(3-4): 1003-1006.

[15] N.S. Shaligram, M.B. Bule, R. Singhal, et al., Biosynthesis of silver nanoparticles using aqueous extract from the compactin producing fungal strain. Process Biochemistry, 2009, 44(8): 939-943.

[16] M. Fu, Q. Li, D. Sun, et al., Rapid preparation process of silver nanoparticles by bioreduction and their characterizations. Chinese Journal of Chemical Engineering, 2006, 14(1): 114-117.

[17] T. Ogi, Room-temperature synthesis of gold nanoparticles and nanoplates using Shewanella algae cell extract. Journal of Nanoparticle Research, 2010, 12(7): 25312539.

[18] Z. Sadowski, Synthesis of silver nanoparticles using microorganisms. Materials Science-Poland, 2008, 26(2): 419-424.

[19] K.N. Thakkar, S.S. Mhatre, and R.Y. Parikh, Biological synthesis of metallic nanoparticles. Nanomedicine: 
Nanotechnology, Biology and Medicine, 2010, 6(2): 257262.

[20] M. Rai, N. Duran, Metal nanoparticles in microbiology. Springer Science \& Business Media, 2011.

[21] G. Sharma, A.S. Kumar, S. Naushad, et al., Novel development of nanoparticles to bimetallic nanoparticles and their composites: A review. Journal of King Saud University-Science, 2017.

[22] S. Neethirajan, M.A. Clond, and A. Vogt, Medical biofilms - nanotechnology approaches. Journal of Biomedical Nanotechnology, 2014, 10(10): 2806-2827.

[23] M. Rai, A. Yadav, and A. Gade, Silver nanoparticles as a new generation of antimicrobials. Biotechnology Advances, 2009, 27(1): 76-83.

[24] H.H. Lara, E.N. Garza-Treviño, L. Ixtepan-Turrent, et al., Silver nanoparticles are broad-spectrum bactericidal and virucidal compounds. Journal of Nanobiotechnology, 2011, 9(1): 30 .

[25] S. Tang, J. Zheng, Antibacterial activity of silver nanoparticles: Structural effects. Advanced Healthcare Materials, 2018: 1701503.

[26] S.O. Hasson, Phenotypic and genotypic detection of biofilm formation Pseudomonas oryzihabitance and susceptibility to antibiotics. Nano Biomed. Eng., 2019, 11(1): 11-17.

[27] I.H. Al-Azawi, A.H. Al-Hamadani, and S.O. Hasson, Association between biofilm formation and susceptibility to antibiotics in Staphylococcus lentus isolated from urinary catheterized patients. Nano Biomed. Eng., 2018, 10(2): 97-103.

[28] S.O. Hasson, A.H. Al-Hamadani, and I.H. Al-Azawi, Occurrence of biofilm formation in Serratia fonticola and Pantoea sp. isolates among urinary catheterized patients. Nano Biomed. Eng., 2018, 10(3): 295-304.

[29] CLSI, Performance standards for antimicrobial susceptibility testing. M100. Clinical and Laboratory Standards Institute, Wayne, PA., 2017.

[30] E.Z. Gomaa, Antimicrobial, antioxidant and antitumor activities of silver nanoparticles synthesized by Allium cepa extract: A green approach. Journal of Genetic Engineering and Biotechnology, 2017, 15(1): 49-57.

[31] P. Verma, Methods for determining bactericidal activity and antimicrobial interactions: synergy testing, time-kill curves, and population analysis. CRC Press, New York, USA, 2007: 275-290.

[32] F.P. Mehr, M. Khanjani, and P. Vatani, Synthesis of nanoAg particles using sodium borohydride. Oriental Journal of Chemistry, 2015, 31(3): 1831-1833.

[33] K. Kalimuthu, Biosynthesis of silver nanocrystals by Bacillus licheniformis. Colloids and Surfaces B: Biointerfaces, 2008, 65(1): 150-153.

[34] N. Durán, P.D. Marcato, O.L. Alves, et al., Mechanistic aspects of biosynthesis of silver nanoparticles by several Fusarium oxysporum strains. Journal of Nanobiotechnology, 2005, 3(1): 8.

[35] C. Wang, Green synthesis of silver nanoparticles by Bacillus methylotrophicus, and their antimicrobial activity. Artificial Cells, Nanomedicine, and Biotechnology, 2016, 44(4): 1127-1132.

[36] B. Kumar, K. Smita, L. Cumbal, et al., Fabrication of silver nanoplates using Nephelium lappaceum (Rambutan) peel: a sustainable approach. Journal of Molecular Liquids, 2015, 211: 476-480.

[37] S. Gurunathan, J.W. Han, D.-N. Kwon, et al., Enhanced antibacterial and anti-biofilm activities of silver nanoparticles against Gram-negative and Gram-positive bacteria. Nanoscale Research Letters, 2014, 9(1): 373.

[38] R. Ghotaslou, Z. Bahari, The in vitro effects of silver nanoparticles on bacterial biofilms. The Journal of Microbiology, Biotechnology and Food Sciences, 2017, 6(4): 1077.

[39] G. Martinez-Castanon, N. Nino-Martinez, F. MartinezGutierrez, et al., Synthesis and antibacterial activity of silver nanoparticles with different sizes. Journal of Nanoparticle Research, 2008, 10(8): 1343-1348.

[40] M. Ferrari, Nanogeometry: Beyond drug delivery. Nature Nanotechnology, 2008, 3(3): 131.

[41] W. Jiang, B.Y.S. Kim, R.J.T. Chan, et al., Nanoparticlemediated cellular response is size-dependent. Nature Nanotechnology, 2008, 3(3): 145.

[42] I. Sondi, B. Salopek-Sondi, Silver nanoparticles as antimicrobial agent: a case study on E. coli as a model for Gram-negative bacteria. Journal of Colloid and Interface Science, 2004, 275(1): 177-182.

[43] N. Beyth, Y.D. Houri-Haddad, A. Khan, et al., Alternative antimicrobial approach: Nano-antimicrobial materials. Evidence-Based Complementary and Alternative Medicine, 2015.

[44] C. Buzea, I.I. Pacheco, and K. Robbie, Nanomaterials and nanoparticles: sources and toxicity. Biointerphases, 2007, 2(4): MR17-MR71.

[45] C.-N. Lok, C.-M. Ho, R. Chen, et al., Proteomic analysis of the mode of antibacterial action of silver nanoparticles. Journal of Proteome Research, 2006, 5(4): 916-924.

[46] S. Shrivastava, T.R. Bera, A. Singh, et al., Characterization of enhanced antibacterial effects of novel silver nanoparticles. Nanotechnology, 2007, 18(22): 225103.

[47] Y.-G. Yuan, Q.-L. Peng, and S. Gurunathan, Effects of silver nanoparticles on multiple drug-resistant strains of Staphylococcus aureus and Pseudomonas aeruginosa from mastitis-infected goats: An alternative approach for antimicrobial therapy. International Journal of Molecular Sciences, 2017, 18(3): 569.

[48] J. Jiang, G. Oberdörster, and P. Biswas, Characterization of size, surface charge, and agglomeration state of nanoparticle dispersions for toxicological studies. Journal of Nanoparticle Research, 2009, 11(1): 77-89.

[49] B. Le Ouay, F. Stellacci, Antibacterial activity of silver nanoparticles: A surface science insight. Nano Today, 2015, 10(3): 339-354.

[50] S. Gurunathan, Rapid biological synthesis of silver nanoparticles and their enhanced antibacterial effects against Escherichia fergusonii and Streptococcus mutans. Arabian Journal of Chemistry, 2014.

Copyright $\subseteq$ Shaimaa Obaid Hasson, Mohammed Jabber AlAwady, Mohanad Jawad Kadhim, and Hayder Shkhair AlJanabi. This is an open-access article distributed under the terms of the Creative Commons Attribution License, which permits unrestricted use, distribution, and reproduction in any medium, provided the original author and source are credited. 